\title{
Commentary: Optimize the speed, enhance the patient's life
}

\author{
Jason J. Han, MD, and Pavan Atluri, MD
}

\footnotetext{
From the Division of Cardiovascular Surgery, Department of Surgery, University of Pennsylvania, Philadelphia, $\mathrm{Pa}$.

Disclosures: Authors have nothing to disclose with regard to commercial support.

Received for publication June 17, 2019; accepted for publication June 18, 2019; available ahead of print July 30, 2019.

Address for reprints: Pavan Atluri, MD, Division of Cardiovascular Surgery, Hospital of the University of Pennsylvania, 3400 Spruce St, 6 Silverstein Pavilion, Philadelphia, PA 19104 (E-mail: Pavan.Atluri@uphs.upenn. edu).

J Thorac Cardiovasc Surg 2020;159:1326-7

$0022-5223 / \$ 36.00$

Copyright $(2) 2019$ by The American Association for Thoracic Surgery

https://doi.org/10.1016/j.jtcvs.2019.06.065
}

The field of mechanical circulatory support has undergone a rapid evolution during the past 2 decades. Newer generations of left ventricular assist devices (VADs) only continue to grow safer and more durable, with median survival now approaching 5 years for patients receiving them as destination therapy. ${ }^{1-3}$ Even as the volume of available donor organs for heart transplantation remains stagnant, left VAD therapy offers a compelling alternative and, eventually, perhaps a substitute. If the previous decade of mechanical circulatory support can be characterized by increase in survival, however, the prominent challenge of the coming decade will be to reduce further the burden of adverse events and thereby to optimize quality of life for these patients. ${ }^{4,5}$ Given their severity of heart failure and multiorgan dysfunction, rendered more complex by introduction of a hybrid physiology, this patient population is one of the most challenging to manage, especially on an outpatient basis. At 1 year, the rate of rehospitalization remains as high as $65 \%$ to $80 \%$, regardless of device type, which undoubtedly carries negative prognostic implications. ${ }^{5}$

The expert opinion by Cowger and colleagues ${ }^{6}$ in this issue of the Journal is an astute and timely rallying call for a paradigm shift in VAD management toward this goal. Current evidence suggests that a significant number of patients with VADs may be living with suboptimal device settings from a hemodynamic standpoint, which may lead to limited activity or to more frequent heart failure exacerbations. ${ }^{7,8}$ The solution to this problem requires recognizing that left VAD therapy is a dynamic process. Although to an extent device function is inherently sensitive to the patient's preload, afterload, and native contractility, device parameters also need to be adjusted by clinicians in accordance with the patient's physiology, including volume status and right heart function. Although these factors are already closely monitored in an intensive care unit setting, Cowger and colleagues ${ }^{6}$ contend that there is

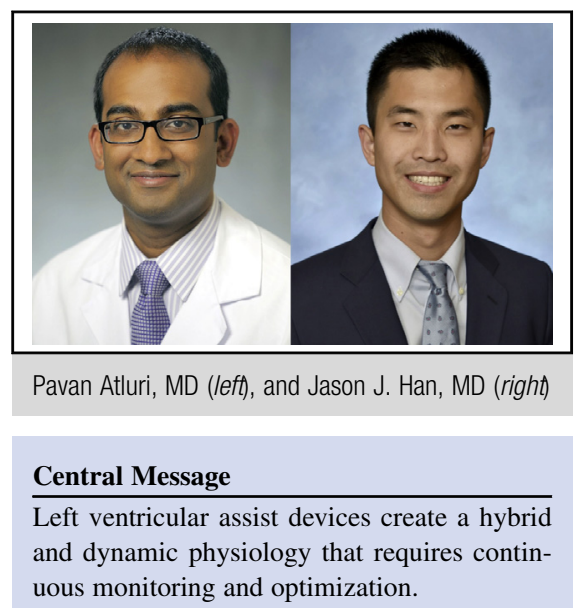

See Article page 1322. a need to extrapolate the benefits of hemodynamically guided VAD speed changes more readily to the outpatient setting as indicated. For those whose heart failure symptoms are persistent, requiring significant changes in medical therapy, and for whose device alarms continue to blare, the threshold for evaluating hemodynamic status in the form of a right heart catheterization procedure ought to be lowered. As such, conceptualizing hemodynamically guided VAD speed changes before a patient's condition deteriorates further as a preemptive optimization strategy may lead to overall reduction in VAD-related adverse events and an improvement in quality of life, although its true effect remains to be evaluated prospectively in larger cohorts. ${ }^{8,9}$ This preemptive strategy has been an integral practice at our institution during the last 5 years, as we have grown more enthusiastic about evaluating hemodynamics in our patients with VADs, which has often led to changes in our management that would not have been apparent with other modalities.

Ultimately, Cowger and colleagues ${ }^{6}$ deserve our congratulations for their important contribution, which highlights a prominent challenge in the chronic management of patients with VADs as the therapy grows more prevalent and durable. As our noninvasive diagnostic tools become more reliable, we one day may be able to rely less on hemodynamics. ${ }^{10}$ As VAD technology continues to become more sophisticated, we one day may be able to "set it and forget it." Until then, however, we must remain vigilant. 
This is a patient population that needs timely and accurate reassessments and fine-tuning to achieve their true potential.

\section{References}

1. Kormos RL, Cowger J, Pagani FD, Teuteberg JJ, Goldstein DJ, Jacobs JP, et al. The Society of Thoracic Surgeons Intermacs Database annual report: evolving indications, outcomes, and scientific partnerships. Ann Thorac Surg. 2019;107: 341-53.

2. Mehra MR, Goldstein DJ, Uriel N, Cleveland JC Jr, Yuzefpolskaya M, Salerno C, et al. MOMENTUM 3 Investigators. Two-year outcomes with a magnetically levitated cardiac pump in heart failure. N Engl J Med. 2018;378:1386-95.

3. Milano CA, Rogers JG, Tatooles AJ, Bhat G, Slaughter MS, Birks EJ, et al. ENDURANCE Investigators. HVAD: the ENDURANCE supplemental trial. JACC Heart Fail. 2018;6:792-802.

4. Han JJ, Acker MA, Atluri P. Left ventricular assist devices. Circulation. 2018; $138: 2841-51$.
5. Kirklin JK, Pagani FD, Kormos RL, Stevenson LW, Blume ED, Myers SL, et al. Eighth annual INTERMACS report: special focus on framing the impact of adverse events. J Heart Lung Transpl. 2017;36:1080-6.

6. Cowger JA, Grafton G, Shah P. Avoiding the "set it and forget it mentality": need to regularly reassess left ventricular assist device patients for optimal support. J Thorac Cardiovasc Surg. 2020;159:1322-5.

7. Shah P, Badoe N, Phillips S, Abdullah K, May CW, Nabut JL, et al. Unrecognized left heart failure in LVAD recipients: the role of routine invasive hemodynamic testing. ASAIO J. 2018;64:183-90.

8. Couperus LE, Delgado V, Khidir MJH, Vester MPM, Palmen M, Fiocco M, et al. Pump speed optimization in stable patients with a left ventricular assist device. ASAIO J. 2017;63:266-72.

9. Apostolo A, Paolillo S, Contini M, Vignati C, Tarzia V, Campodonico J, et al. Comprehensive effects of left ventricular assist device speed changes on alveolar gas exchange, sleep ventilatory pattern, and exercise performance. J Heart Lung Transpl. 2018;37:1361-71.

10. Estep JD, Vivo RP, Krim SR, Cordero-Reyes AM, Elias B, Loebe M, et al. Echocardiographic evaluation of hemodynamics in patients with systolic heart failure supported by a continuous-flow LVAD. J Am Coll Cardiol. 2014;64:1231-41. 